\title{
High maternal and neonatal mortality rates in northern Nigeria: an 8-month observational study
}

This article was published in the following Dove Press journal:

International Journal of Women's Health

12 August 2013

Number of times this article has been viewed

\author{
Gilles Guerrier' \\ Bukola Oluyide ${ }^{2}$ \\ Maria Keramarou' \\ Rebecca Grais' \\ 'Epicentre, Paris, France; \\ 2 Médecins Sans \\ Frontières, Paris, France
}

\begin{abstract}
Background: Despite considerable efforts to reduce the maternal mortality ratio, numerous pregnant women continue to die in many developing countries, including Nigeria. We conducted a study to determine the incidence and causes of maternal mortality over an 8-month period in a rural-based secondary health facility located in Jahun, northern Nigeria.
\end{abstract}

Methods: A retrospective observational study was performed in a 41-bed obstetric ward. From October 2010 to May 2011, demographic data, obstetric characteristics, and outcome were collected from all pregnant women admitted. The total number of live births during the study period was recorded in order to calculate the maternal mortality ratio.

Results: There were 2,177 deliveries and 39 maternal deaths during the study period, with a maternal mortality ratio of $1,791 / 100,000$ live births. The most common causes of maternal mortality were hemorrhage (26\%), puerperal sepsis (19\%), and obstructed labor (5\%). No significant difference $(P=0.07)$ in mean time to reach the hospital was noted between fatal cases (1.9 hours, 95\% confidence interval [CI] 1.1-2.6) and nonfatal cases (1.4 hours, 95\% CI 1.4-1.5). Two hundred and sixty-six women were admitted presenting with stillbirth. Maternal mortality was higher for unbooked patients than for booked patients (odds ratio 5.1, 95\% CI 3.5-6.2, $P<0.0001)$. The neonatal mortality rate was calculated at 46/1,000 live births. The main primary causes of neonatal deaths were prematurity (44\%) and birth asphyxia (22\%).

Conclusion: Maternal and neonatal mortality remains unacceptably high in this setting. Reducing unbooked emergencies should be a priority with continuous programs including orthodox practices in order to meet the fifth Millennium Development Goal.

Keywords: fetal mortality, maternal mortality, Nigeria, antenatal care

\section{Introduction}

Despite considerable efforts to reduce the maternal mortality ratio (MMR) by three quarters from 1990 to 2015 in order to meet the fifth Millennium Development Goal, ${ }^{1}$ an unacceptable number of pregnant women continue to die in many developing countries, including Nigeria. ${ }^{2}$ It is suggested that pregnancy-related mortality is due to delays in seeking required medical help, seeking a medical facility in time, and receiving adequate care. ${ }^{3}$ However, this "three delays" model may appear as an oversimplified scheme since complex factors affect each level of care. ${ }^{4}$ Specific reasons may explain this alarming situation in Nigeria, including low socioeconomic status, absence of emergency obstetric care, deterioration of hospital staffing in rural areas partly due to overseas emigration of Nigerian doctors, lack of access linked to transport and communication problems, and traditional beliefs delaying referral of complicated cases and utilization of available obstetric facilities. Little data are available regarding 
maternal and perinatal mortality in rural areas of northern Nigeria. This study was undertaken to assess maternal and perinatal mortality rates and explore causes of deaths (both maternal and neonatal) in a recently equipped rural hospital in Jahun, Jigawa State.

\section{Materials and methods}

\section{Setting}

An emergency obstetric and neonatal care program operated by Médecins Sans Frontières has been running in Jahun, Jahun local government area, Jigawa State, Nigeria, since July 2008. The catchment area for which this primary hospital serves is approximately 380,000 persons (combining Jahun and Miga local government areas). ${ }^{5}$ The capacity of this secondary health facility is a 41-bed ward (35 standard beds and six intensive care unit beds) with a neonatal care unit, using qualified doctors (two obstetricians and two anesthetists), seven midwives (trained to manage labor and delivery and to assist newborns), and four nurse assistants (trained to assist mothers and help midwives) per shift. Management of normal deliveries, use of partographs, and routine newborn care are provided. The program also includes management of resuscitation of mother and baby. Injectable antibiotics, oxytocin, anticonvulsants, and safe blood transfusion are available. A surgical facility is operational for cesarean sections, ectopic pregnancies, ruptured uterus, and septic debridement, among other obstetric complications.

\section{Study design}

A retrospective data collection was performed including all pregnant women admitted to Jahun Hospital from October 2010 to May 2011. General demographic characteristics (maternal age, ethnicity, home village), parity, number of antenatal clinic attendances, use of traditional treatments, time to reach hospital, delivery details, and outcome (maternal and neonatal) were recorded. The primary outcome of the study was to estimate MMR.

\section{Definitions}

Maternal death was defined as death occurring during pregnancy, labor, or within 42 days of delivery, inclusive of ectopic pregnancy and abortion. Causes of maternal death were divided into direct causes (eg, hemorrhage, obstructed labor, sepsis, ectopic rupture, sepsis, pregnancy-induced hypertension, amniotic fluid embolism, pulmonary embolism) and indirect causes (eg, anemia, cardiovascular disease).

Neonatal death was defined as death occurring within the 28 first days of life. The primary causes of neonatal death were broadly grouped under four major headings, ie, birth asphyxia, sepsis (pneumonia, septicemia, meningitis), prematurity, and others. Neonatal mortality was divided in early (death of a live-born neonate within the first 7 days of life) and late (after 7 days until before 28 days).

The total number of live births during the study period was recorded in order to calculate the MMR. The MMR was defined as the annual number of female deaths per 100,000 live births from any cause related to or aggravated by pregnancy, and the neonatal mortality rate was defined as the annual number of deaths during the first 28 days of life (0-27 days) per 1,000 live births. The primary cause of neonatal mortality was the main outcome of interest and was defined as "a disease or injury which initiated the train of morbid events leading directly to death".

\section{Statistical analysis}

The data were analyzed using Stata version 11 (Stata Corporation, TX, USA). Quantitative variables were summarized using the range, mean, and standard deviation. Categorical variables were tabulated using frequencies and percentages. The Student's $t$-test was used for testing the significance of associations between continuous variables.

\section{Results}

During the study period, a total of 2,324 women gave birth to 2,177 live births (including 129 twins), and 269 stillbirths (including four twins). Thirty-nine maternal deaths were recorded. The overall MMR was 39/2,177 live deliveries $\times 100,000=1,791 / 100,000$ live births. The MMR was highest in those aged below 20 years (Table 1). Primiparous patients had the highest MMR at 2,299, while grandmultiparous patients (parity 5 and above) had an MMR of 1,724 (Figure 1). The clinical causes of death are shown in Table 2. Direct causes of death included hemorrhage (antepartum and postpartum, $n=13,35 \%)$, puerperal sepsis $(n=7,19 \%)$, obstructed labor $(n=2,5 \%)$, severe pre-eclampsia/eclampsia $(n=1,3 \%)$, and ectopic rupture $(n=1,3 \%)$. Indirect causes of maternal death included anemia $(n=3,8 \%)$ and

Table I Maternal mortality ratio and patient age

\begin{tabular}{llll}
\hline $\begin{array}{l}\text { Age, } \\
\text { years }\end{array}$ & $\begin{array}{l}\text { Live births } \\
(\mathbf{n}=\mathbf{2 , 1 7 7 )}\end{array}$ & $\begin{array}{l}\text { Maternal deaths } \\
(\mathbf{n}=\mathbf{3 3}) *\end{array}$ & MMR/I 00,000 \\
\hline$<20$ & 724 & 18 & 2,486 \\
$20-29$ & 778 & 8 & 1,028 \\
$30-39$ & 554 & 6 & 1,083 \\
$\geq 40$ & 121 & $\mathrm{I}$ & 826 \\
\hline
\end{tabular}

Note: *Six cases with no age reported.

Abbreviation: MMR, maternal mortality ratio. 


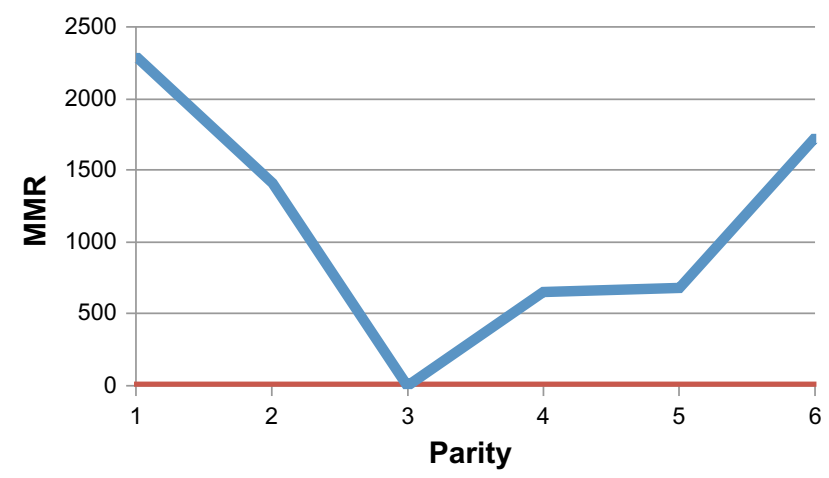

Figure I Relationship between parity and MMR. Abbreviation: MMR, maternal mortality ratio.

cardiovascular disease $(n=2,5 \%)$. The cause of maternal death was undetermined in 13 (33\%) cases. There were 153 cesarean sections and three maternal deaths, with an MMR of 2,000. Causes of maternal death occurring after cesarean section were not anesthesia-related and included hemorrhage $(\mathrm{n}=2)$ and potential amniotic fluid embolism $(\mathrm{n}=1)$. There were 2,302 vaginal deliveries and 24 maternal deaths, with an MMR of 1,043 . No significant difference $(P=0.07)$ in mean time to reach the hospital was noted between fatal cases (1.9 hours, $95 \%$ confidence interval [CI] 1.1-2.6) and nonfatal cases (1.4 hours, 95\% CI 1.4-1.5). Two hundred and sixty-nine women were admitted presenting with stillbirth. Among them, $12 \%$ had severe pre-eclampsia or eclampsia.

During the period of the study, a total of 2,177 infants were born to women admitted in the hospital, $79 \%$ of whom were in-born (delivered in the Médecins Sans Frontières Clinic) and 20\% were out-born (home or health center). The gender ratio was 1.3:1 in favor of males. There were 269 stillbirths and 101 deaths recorded, corresponding to a neonatal mortality rate of 46/1,000 live births. The main primary causes of neonatal deaths were prematurity $(n=44$, $62 \%)$ and birth asphyxia $(n=22,31 \%)$, while other causes included infection $(\mathrm{n}=25)$, congenital abnormality $(\mathrm{n}=2)$

Table 2 Clinical causes of maternal deaths $(n=39)$

\begin{tabular}{lll}
\hline Cause of death & $\mathbf{n}$ & $\%$ \\
\hline Direct & 10 & \\
$\quad$ Hemorrhage & 7 & 26 \\
Sepsis & 2 & 19 \\
Obstructed labor & 1 & 5 \\
Eclampsia & 1 & 3 \\
$\quad$ Ectopic rupture & & 3 \\
Indirect & 3 & \\
$\quad$ Anemia & 2 & 5 \\
Cardiovascular disease & 13 & 33 \\
$\quad$ Undetermined & 39 & 100 \\
Total & & \\
\hline
\end{tabular}

and undetermined cause $(n=6$, Table 3$)$. Early neonatal death accounted for $70 \%(n=71)$ of the neonatal mortality. Since no birth weights were recorded, no analysis in different birth weight groups was possible. Patients presenting with a stillbirth showed no significant difference in mean time to reach the hospital compared with women presenting with a live birth.

\section{Discussion}

The finding in this MMR study of 1,791/100,000 live births confirms that maternal mortality is a very serious public health problem in the northern Nigeria region. This area is reported to have the highest rate of maternal mortality compared with the rest of the country. ${ }^{6,7}$ When compared with reports from Nigeria, this study shows a $2-3$-fold increase over the ratio obtained in other parts of the country. ${ }^{8-10}$ However, this MMR falls within the country's MMR, which ranges between 460 and 2,200 with an average of 1,100. ${ }^{11}$ The high maternal mortality is certainly associated with the high proportion of unbooked patients presenting to hospital when their life is already endangered by advanced pregnancy complications. Because follow-up in the antenatal clinic during pregnancy appeared to be significantly associated with a reduction in hypertensive disorders in another study performed in the same setting, ${ }^{12}$ the role of antenatal care in bringing about a reduction in maternal death is a point for discussion. During the period of antenatal care, it is possible to identify some of the conditions that may lead to maternal complications and death; for instance, warning signs such as headache, blurred vision, hypertension, epigastric pain, and proteinuria are easily identifiable signs that may be managed to prevent eclampsia occurring. In addition, appropriate antenatal care might reduce the number of stillbirths observed in our study.

Severe hemorrhage was the leading direct cause of death in our study. Despite active management of the third stage of labor performed by skilled health professionals, involving administration of oxytocin, delivery of the placenta by control cord traction, and uterine massage, blood transfusion

Table 3 Clinical causes of neonatal deaths in Jahun maternity ward, October 2010 to May 2011 ( $(n=76)$

\begin{tabular}{lll}
\hline $\begin{array}{l}\text { Leading cause } \\
\text { of neonatal death }\end{array}$ & $\begin{array}{l}\text { Within 0-7 days, } \\
\mathbf{n}(\%)\end{array}$ & $\begin{array}{l}\text { Within 8-28 days, } \\
\mathbf{n}(\%)\end{array}$ \\
\hline Prematurity & $44(62)$ & $2(7)$ \\
Asphyxia & $22(3 \mathrm{I})$ & 0 \\
Other cause* & $5(7)$ & $28(93)$ \\
Total $(\mathrm{n}=10 \mathrm{I})$ & $7 \mathrm{I}$ & 30 \\
\hline \multicolumn{2}{l}{ Note: $*$ infection, congenital abnormality, undetermined. }
\end{tabular}


and hysterectomy were performed when management of third stage labor was inefficient. Most women with this fatal issue died within 24 hours of admission and were in poor general condition at the time of presentation.

Due to the absence of biological results and lack of post mortem services, the precise causes of death were difficult to ascertain in a significant number of cases. According to a recent monitoring of maternal deaths in northern Nigeria, the leading direct causes of fatal outcome in the region are hemorrhage and pre-eclampsia/eclampsia, while anemia is the main indirect cause of maternal death. ${ }^{13}$ Surprisingly, severe pre-eclampsia/eclampsia did not appear to be a major cause of maternal death in our study. In contrast, recent studies performed in Nigeria among women with eclampsia reported an approximate $20 \%$ fatality case rate (mainly from pulmonary edema and renal failure). ${ }^{14}$ This difference could be the result of standardized procedures using efficient drugs such as magnesium sulfate and appropriate medical care provided by skilled staff in Jahun. Another reason to explain our finding may be that pre-eclampsia/eclampsia cases were overdiagnosed.

The results obtained in this hospital-based study may possibly overestimate the MMR, given that the center admits complicated cases with a high risk of death. However, this analysis provides useful information regarding the epidemiology and underlying causes of death in order to optimize the existing health care facilities and training requirements for health care providers. Primiparous and grandmultiparous women have the highest MMR. There is a greater burden of maternal death in the youngest age groups than other age groups. This may be due to the generally low age at marriage, a typical occurrence in rural northern Nigerian settings. ${ }^{15}$ The association between early childbearing, adverse pregnancy outcomes, and high maternal mortality has been established. ${ }^{16,17}$ Delaying pregnancy, education of women, and community-based interventions to implement family planning appear to be priorities in an attempt to reduce maternal mortality.

Traditional birth attendants should be integrated into the health system and need to be trained to recognize obstetric emergencies, including sepsis, which appears to be a major cause of death in our study. Interestingly, fatal cases in our study did not travel longer than nonfatal cases before reaching the hospital. Unfortunately, the duration of labor (or onset of complications) prior to presentation was not recorded in our study, because this would have well described the contribution of other factors outside the health facility to maternal and neonatal outcome. A high proportion of women were seeking traditional treatment before delivery while experiencing a major complication. ${ }^{12}$

Health workers must address the sociocultural factors that restrict utilization of health care facilities with communities to improve acceptance of and demand for hospital deliveries. In addition to prevention, improving communication systems and upgrading roads and emergency transportation is likely to reduce maternal and neonatal mortality.

The neonatal mortality rate observed in our study was twice as high as the national rates reported by the World Health Organization in 2008 and the United Nations Children's Fund in 2009 (48/1,000 and 39/1,000 live births, respectively). ${ }^{11,18}$ Leading causes of neonatal death were asphyxia, prematurity, and sepsis. Newborn units in other Nigerian centers have reported similar findings. ${ }^{19,20}$ Life-threatening conditions, such as birth asphyxia and sepsis, are potentially treatable, even in a modestly equipped health facility for newborn patients (no neonatal ventilator or facilities for surfactant therapy). Efforts need to be made to educate health care providers in identifying and managing such conditions. The very low proportion of sepsis as a cause of neonatal death might be explained by the very short period of follow-up of newborns.

Our study has two main limitations. First, the hospitalbased approach includes bias of the sample population. Many women and neonates die in rural Africa without presenting to a modern health service. Community-based studies are a better instrument in order to explore the actual mortality rates. Second, due to time and financial restrictions, the sample size in our study was limited. Finally, there are no available data regarding maternal and perinatal mortality rates at the health facility in Jahun before emergency obstetric and neonatal care intervention to assess the impact of the program on maternal health. However, it is most likely that obstetric and pediatric care were improved, given that the hospital was poorly equipped before 2008 (eg, no running operating rooms for cesarean sections). Moreover, this study provides a useful indication of the challenges faced by this rural area in Nigeria characterized by poor attitudes towards seeking health care.

Most of the maternal deaths recorded in our study were due to preventable/treatable causes, while the neonatal death rate was higher than in other parts of Nigeria. Médecins Sans Frontières subsequently developed mobile clinics dedicated to remote areas in the Jahun and Miga local government areas, encouraging women to seek antenatal care outside their immediate community, promoting early referral, reducing the proportion of unbooked women, developing 
standardized risk assessment to identify women with a higher than normal risk of developing obstetric complications, and encouraging planned deliveries in women with high-risk pregnancies. Preliminary results of such prehospital care are promising. However, alongside these local actions, a strong and sustainable political commitment is required to take up all the necessary measures to improve maternal health in this part of Nigeria.

\section{Acknowledgments}

We greatly acknowledge the Médecins Sans Frontières staff and all the dedicated Nigerian field workers and translators who assisted with this project.

\section{Author contributions}

GG, BO, and RG designed the study, and BO undertook the data collection. Analysis and interpretation was done by $\mathrm{GG}$, $\mathrm{BO}$, and MK. GG and MK drafted the manuscript, which was critically revised by BO and RG. All authors gave their final approval for publication of the manuscript.

\section{Disclosure}

The authors declare that they have no competing interests in this work.

\section{References}

1. United Nations General Assembly. United Nations Millennium Declaration. A/RES/55/2. New York, NY: United Nations; 2000. Available from: http://www.un.org/millennium/declaration/ares552e. htm. Accessed July 29, 2013.

2. Doctor HV, Olatunji A, Findley SE, Afenyadu GY, Abdulwahab A, Jumare A. Maternal mortality in northern Nigeria: findings of a health and demographic surveillance system in Zamfara State, Nigeria. Trop Doct. 2012;42(3):140-143.

3. Thaddeus S, Maine D. Too far to walk: maternal mortality in context. Soc Sci Med. 1994;38(8):1091-1110.

4. Bhutta ZA. Seeing the unseen: targeting neonatal mortality in rural Vietnam. Glob Health Action. 2011;4.

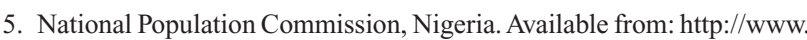
population.gov.ng/. Accessed August 7, 2013.

6. Gharoro EP, Igbafe AA. Pattern of drug use amongst antenatal patients in Benin City, Nigeria. Med Sci Monit. 2000;6(1):84-87.

7. Kullima AA, Kawuwa MB, Audu BM, Geidam AD, Mairiga AG. Trends in maternal mortality in a tertiary institution in Northern Nigeria. Ann Afr Med. 2009;8(4):221-224.

8. Onah HE, Okaro JM, Umeh U, Chigbu CO. Maternal mortality in health institutions with emergency obstetric care facilities in Enugu State, Nigeria. J Obstet Gynaecol. 2005;25(6):569-574.

9. Aboyeji AP, Ijaiya MA, Fawole AA. Maternal mortality in a Nigerian teaching hospital - a continuing tragedy. Trop Doct. 2007;37(2): 83-85.

10. Ezugwu EC, Onah HE, Ezugwu FO, Okafor II. Maternal mortality in a transitional hospital in Enugu, south east Nigeria. Afr J Reprod Health. 2009;13(4):67-72.

11. World Health Organization, Department of Making Pregnancy Safer, Nigeria Country Profile 2008. Available from: http//www.who.int/making pregnancy safer/countries/nig.pdf. Accessed August 7, 2013.

12. Guerrier G, Oluyide B, Keramarou M, Grais R. Factors associated with severe preeclampsia and eclampsia in Jahun, Nigeria. Int $J$ Women's Health. 2013;5:1-5.

13. Okusanya BO, Aigere EO, Abe A, Ibrahim HM, Salawu RA. Maternal deaths: initial report of an on-going monitoring of maternal deaths at the Federal Medical Centre Katsina, Northwest Nigeria. J Matern Fetal Neonatal Med. 2013;26(9):885-888.

14. Adamu AN, Ekele BA, Ahmed Y, Mohammed BA, Isezuo SA, Abdullahpi AA. Pregnancy outcome in women with eclampsia at a tertiary centre in northern Nigeria. Afr J Med Med Sci. 2012;41(2): 211-219.

15. Rai RK, Singh PK, Singh L. Utilization of maternal health care services among married adolescent women: insights from the Nigeria Demographic and Health Survey, 2008. Womens Health Issues. 2012;22(4): e407-e414.

16. Omar K, Hasim S, Muhammad NA, Jaffar A, Hashim SM, Siraj HH. Adolescent pregnancy outcomes and risk factors in Malaysia. Int $J$ Gynaecol Obstet. 2010;111(3):220-223.

17. Rasheed S, Abdelmonem A, Amin M. Adolescent pregnancy in Upper Egypt. Int J Gynaecol Obstet. 2011;112(1):21-24.

18. United Nations General Assembly. United Nations Millenium Declaration. A/RES/55/2. New York: UN, 2000.

19. Obi SN, Onyire BN. Pattern of neonatal admission and outcome at a Nigerian tertiary health institution. Orient J Med. 2004;16:31-37.

20. Ojukwu JU, Ogbu CN. Analysis and outcome of admissions in the special care baby unit of Ebony State University Teaching Hospital, Abakaliki. J College Med. 2004;9:23-25.
International Journal of Women's Health

\section{Publish your work in this journal}

The International Journal of Women's Health is an international, peerreviewed open-access journal publishing original research, reports, editorials, reviews and commentaries on all aspects of women's healthcare including gynecology, obstetrics, and breast cancer. The manuscript management system is completely online and includes

\section{Dovepress}

a very quick and fair peer-review system, which is all easy to use. Visit http://www.dovepress.com/testimonials.php to read real quotes from published authors. 